\title{
Plano Diretor: Um personagem a procura de seus autores
}

\section{Luiz Carlos Costa}

Professor Doutor de Planejamento Urbano da FAUUSP

\begin{abstract}
A tese de doutorado que se refere esse artigo, propunha-se estudar como o conceito de plano diretor evoluiu de 1975 a 1989, na ótica de planejadores que nesse período trabalhavam sobre o tema, tendo a cidade de São Paulo por objeto.
\end{abstract}

Para tanto a tese percorre a seguinte trajetória: recupera o quadro de referências que aqueles planejadores dispunham ao iniciarem, no começo dos anos 80, a elaboração de um plano diretor: expõe o conceito de plano diretor adotado nessa ocasião e as premissas em que se apoiou; recupera as referências surgidas na década de 80 relativas ao contexto socioeconômico e político e às experiências de planejamento então realizadas; explicita as novas perspectivas que se abriam para o planejamento urbano estratégico e as condicionantes que este teria de atender em face dos impasses políticos que cercavam a produção do plano; expõe o conceito renovado de plano diretor emergente ao final da década.

Complementarmente, a tese analisa o papel-chave do governante que assumisse, enquanto missão de estado a tarefa de promover a elaboração e instituição do plano diretor, entendido como obra coletiva amplamente socializada.

The thesis analyses the development of the concept of master plan between 1975 and 1989, from the point of view of the planners who worked on the city of São Paulo in that period.

\section{Resumo}


With that objective in mind, the thesis proceeds along the following path

1. It investigates the reference framework those planners had in the early 80's, when they began to work on a Master Plan for São Paulo.

2. It explains the concept of Master Plan which was adopted at the time, as well as its premises.

3. It investigates the preferences developed in the 80's regarding the city's political, economic and social context as well as the planning and experiences carried out at the time.

4. It shows the new perspectives which were open up to strategic planning and its requeriments, if political conflicts underlying the preparation of the plan could be overcome.

5. It shows the renewed concept of Master Plan based in a collective and thoroughly socialised work.

A tese de doutoramento que elaboramos e defendemos em 1995 na FAUUSP teve por propósito central submeter à crítica acadêmica o conceito de plano diretor que havíamos consolidado ao longo de muitos anos de trabalho junto à prefeitura de São Paulo e aos órgãos metropolitanos que ajudamos a criar, como o Gegran e a Emplasa.

Entendemos que a melhor maneira de dar utilidade a uma tese elaborada na presente quadra de nossa vida profissional e acadêmica, seria recuperar a reflexão coletiva realizada sobre o tema em um importante período da história do planejamento da cidade, de forma que pudesse contribuir para o debate recolocado pelo advento do novo século: Que estratégia a decidir e implementar de imediato - permitirá resgatar o imenso potencial de São Paulo no âmbito da economia globalizada e superar os problemas que hoje a estrangulam?

Procuramos dar conta da tarefa atuando de duas maneiras. Primeiro, identificando os documentos das décadas de 70 e 80 que exprimem e atestam a evolução então experimentada pelo conceito de plano diretor. Segundo, prestando um depoimento, como testemunha participante, sobre as percepções, juízos, valores, motivações e dúvidas, que constituíram a referência subjetiva ao trabalho coletivo então realizado.

A tese não pretendeu ser, portanto, um trabalho teórico sobre um instrumento de planejamento abstratamente considerado, mas a 
recuperação crítica de um conceito coletivamente construído em um período histórico determinado, sobre um objeto específico e notável: a maior metrópole do continente. Esperamos, contudo, que o trabalho dê subsídios à elaboração teórica sobre o planejamento urbano, ora desenvolvida por inúmeros pesquisadores em todo o país.

O primeiro capítulo da tese consiste em uma reconstituição das referências presentes nos corações e mentes dos planejadores que retomavam em 1981 a tarefa de elaborar o plano diretor da cidade. Essas referências eram de quatro categorias principais:

a) a crítica desenvolvida nos anos 70 ao chamado planejamento urbano integrado praticado durante os governos autoritários. Essa crítica, elaborada, sobretudo, pelos próprios planejadores, reconhecia que os PDDIs, produzidos sob a pressão política e financeira do governo federal, além de inoperantes para orientar a ação municipal, tinham servido sobretudo para propósitos de mistificação ideológica e manipulação do aparelho de Estado por parte de forças econômicas e políticas dominantes. No caso de São Paulo, as críticas eram ainda mais severas, pois os grandes planos urbanísticos produzidos no final da década de 60 evidenciavam, no irrealismo de suas previsões e proposições, sua alienação ante a realidade social e econômica da metrópole e o propósito predominante de abrir campo para empreendimentos de discutível interesse público.

b) os desafios impostos pela crise urbana manifesta na cidade de São Paulo sob o impacto da crise econômica nacional e internacional que de certa forma inviabilizava o enfrentamento de problemas urbanos-chave legados por mais de três décadas de crescimento urbano acelerado. Eles decorriam do quadro de total liberalidade persistente nesse período em que o poder público concentrava toda sua atenção em obras puntuais omitindo-se claramente no controle dos aspectos sociais, ambientais e funcionais da metrópole. Dentre os problemas-chave de solução impossivel sem uma política global de desenvolvimento urbano, destacavam-se os relativos à habitação popular, aos transportes e trânsito, à drenagem, saneamento e recursos naturais, ao equipamento coletivo, bem como aos custos de urbanização, em contínuo crescimento. Dada a gravidade das demandas em todas essas áreas, considerava-se imprescindível que um plano diretor
Referências obrigatórias para o planejamento de São Paulo 
definisse diretrizes e contribuições consistentes para o encaminhamento das políticas públicas e as integrasse em uma estratégia global.

c) a concepção atualizada do processo social de produção, apropriação e estruturação do espaço construído, entendido como objeto central do planejamento urbano. Entendia-se que a natureza econômica e política desse objeto era fundamental para que se evitasse toda a postura arbitrária, voluntarista ou ingênua, tão freqüente nas anteriores propostas de transformação física da cidade. Dada a importância dos interesses presentes no processo em questão sabia-se que qualquer proposta teria de ser politicamente embasada numa sistemática de negociação entre os diferentes agentes, o que passaria pela demonstração objetiva dos condicionantes e efeitos de cada intervenção.

d) os avanços já logrados no âmbito da tecnoburocracia quanto a estratégias e instrumentos inovadores tratava-se de aproveitar a todo o custo o acúmulo já alcançado nesse âmbito para instrumentar tecnicamente alterações desejadas do processo de produção imobiliária e do equipamento público. As propostas elaboradas aguardavam condições que só o plano diretor poderia proporcionar: sua inserção em elenco coerente de medidas estratégicas transformadoras do processo urbano e uma configuração institucional indispensável a sua eficácia administrativa e jurídica.

O conceito do plano diretor no início dos anos 80
A tese apresenta em seu capítulo 2 o conceito de plano diretor proposto no início dos anos 80 , produzido à luz das referências acima mencionadas.

Esse conceito atribuía especial importância ao caráter integrado do plano e a seu âmbito global e de longo prazo, apontados como indispensáveis para a formulação da política estratégica consistente que caberia consagrar institucionalmente. Ela seria orientada para objetivos escolhidos pela sociedade como prevalentes e definiria ações a serem desenvolvidas pelo poder público, selecionadas pelo critério de sua viabilidade e de seu potencial multiplicador. Valorizava-se, sobretudo, as qualidades de consistência técnica e factibilidade econômica e administrativa do plano, pois se estimava que sua importância política dependeria dele conter respostas eficazes para os desafios sociais gerados 
pela crise urbana e do quanto essas respostas seriam legitimadas em manifestações representativas de toda a coletividade.

Nesse aspecto, apresentando-se como proposta inovadora, capaz de prevenir os riscos das posturas tecnocráticas antes habituais, desagregava o processo de planejamento em duas etapas, ao final das quais as proposições encaminhadas pelo Executivo seriam objeto de apreciação e decisão do Legislativo.

Na primeira etapa, seriam definidos os objetivos e diretrizes gerais de desenvolvimento que passariam a ser prevalentes no período de planejamento escolhido e fundamentariam a nova racionalidade substantiva a ser imprimida ao processo urbano. Nessa oportunidade, as análises e diretrizes formuladas pelo Executivo seriam submetidas à revisão e aprovação da sociedade, que já se teria manifestado também sobre o conteúdo e a metodologia propostos para o plano. Na segunda etapa, proposições relativas a instrumentos e programas de ação concreta seriam definidas em âmbito técnico-administrativo e a seguir submetidas a consultas sistemáticas à coletividade e à decisão final da Câmara de Vereadores.

A tese procura, a seguir, recuperar "As novas referências e perspectivas, surgidas na década de 80 , para o planejamento estratégico da cidade de São Paulo" Inicialmente lembra que foram elaborados quatro projetos de plano diretor que jamais lograram ser legitimados pela sociedade. Dois deles vieram à luz na administração Mário Covas (1983 e 1985) e dois na de Jânio Quadros (1987 e 1988).

O capítulo dá destaque a duas percepções aparentemente contraditórias, que os planejadores passavam a ter a respeito das possibilidades reais de se instituir em São Paulo um plano diretor à altura dos novos desafios gerados pela chamada "década perdida"

Por um lado, o plano diretor parecia ser, nessa década, mais necessário que nunca à sociedade e ao Estado, devido ao agravamento da crise econômica, que aumentava as demandas sociais e reduzia recursos disponíveis, e devido ainda a explosão dos movimentos populares e da sociedade civil, incentivados pela consolidação do regime político democrático. Diante da invia-

Novas referências surgidas para 0 planejamento estratégico da cidade de São Paulo 
bilidade de se atender a essas demandas, evidenciava-se que somente uma ação pública estrategicamente planejada (com grande antecipação e amplitude) poderia aproveitar as tendências do processo urbano e as forças nele atuantes para ampliar os efeitos das intervenções possíveis no sentido de maximizar os resultados escolhidos como prioritários.

Por outro lado porém, percebia-se que, paradoxalmente, a maior parte das forças sociais mostrava-se refratária a idéia de se instituir um plano diretor. Entendíamos que as resistências decorriam, sobretudo de indefinições de natureza política quanto ao processo de tomada de decisões sobre o plano, determinante do sentido e do conteúdo do mesmo. Na verdade, o fracasso das repetidas tentativas governamentais de institui-lo refletia o temor subjacente dele servir apenas a propósitos de mistificação e manipulação por parte das forças que lograssem dominar o processo de sua elaboração.

De fato, era fácil perceber que apesar do plano poder, em princípio, gerar alterações profundas do processo urbano capazes de atingir interesses econômicos e políticos poderosos, ele também poderia, dentro das práticas correntes da realpolitik, ser decidido de forma restrita, ao sabor de influências circunstancialmente dominantes, gerando para a sociedade resultados no mínimo aleatórios.

Assim sendo, estimava-se que entre os atores sociais em presença, não haveriam muitos que quisessem sujeitar-se a esses riscos. Para os que normalmente se beneficiavam do processo urbano corrente (não dependendo do plano para ampliar seus privilégios e vantagens) haveria muito a perder com um plano que pudesse gerar efeitos "fora de controle" Para os que eram normalmente vitimados pela dinâmica urbana - cidadãos e contribuintes em geral e classes populares em especial - não havia clareza nem segurança de que seus interesses seriam atendidos pelo plano, até porque não tinham garantias de que não seriam, mais uma vez, excluídos ou marginalizados, já no processo de elaboração e aprovação do mesmo.

Nesse quadro, os planejadores percebiam que, por mais que o plano diretor se mostrasse necessário ao conjunto da sociedade, ou ainda, por mais que se tivesse criado condições técnicas para sua correta formulação, havia o risco da empreitada da sua produção não ser assumida de fato por nenhuma das forças sociais que teriam interesse concreto ou pleno direto de influir sobre seu 
sentido, seu conteúdo e a própria forma de sua elaboração. Nessas condições o plano se apresentava, como na peça de Pirandello, como um personagem a procura de seus autores.

A tese reconstitui, a seguir, as novas perspectivas que se abriram na década de 80 para o planejamento urbano estratégico. Elas seriam fundamentais para uma nova concepção do plano diretor da cidade, adequada às possibilidades criadas pelo contexto histórico de então, concepção que se exprimiria em 1989 de forma diferente da proposta em 1983.

Parecia agora essencial que o plano diretor passasse a ser entendido não como um conjunto de estudos e "propostas" preparado pelo Executivo e oferecido ao debate público e à decisão do Legislativo -, mas como um conjunto articulado de decisões politicamente assumidas pelas forças sociais, a cada momento da progressiva formulação de cada um dos elementos básicos do plano. Elementos que abrangeriam: os objetivos e princípios consagrados como prevalentes, as diretrizes estratégicas gerais delineadas para realizá-los com os recursos disponíveis no período, as políticas públicas interdependentes a adotar, notadamente as políticas habitacional, de transportes e vias, de saneamento e meio ambiente e a política imobiliária e fundiária, bem como o plano urbanístico a implementar e o sistema de planejamento e gestão a instituir em caráter permanente.

Nessa perspectiva, ficava claro que as predefinições sobre o produto perdiam importância ante aquelas relativas ao processo de planejamento, principalmente porque era neste processo que se conseguiria a participação social essencial à legitimação das decisões.

Uma vez que o plano afirmava seu caráter de obra coletiva, o processo democrático de sua produção e instituição poderia constituir uma experiência cultural e política especialíssima, em face da qual todos os segmentos da sociedade seriam responsáveis: Especialíssima, por se propor chegar a um projeto de cidade escolhido por toda a coletividade e a uma estratégia de implementação a ser obrigatoriamente seguida, a longo prazo, por diferentes administrações. E especialíssima, sobretudo, por abranger um progressivo envolvimento, mobilização e capacitação dos diferentes atores sociais que se dispusessem a partilhar a autoria do plano.

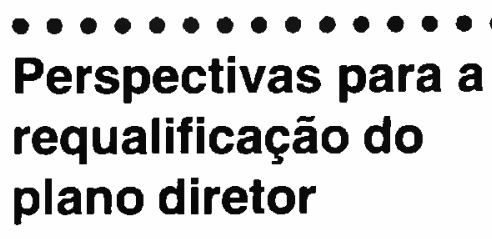

plano diretor 
Nesse sentido, a tese aponta como desafio mais importante, colocado à sociedade e ao Estado fazer da elaboração do plano um empreendimento confiável, não só no aspecto técnico e administrativo, como também no político. Para tanto sua objetividade, legitimidade e operacionalidade teriam de ser suficientemente demonstradas a fim de que se pudesse obter a participação de todas as forças sociais relevantes para o processo urbano. À medida que, com essas garantias, fosse ensejada a maior socialização possível do empreendimento, maiores seriam os avanços alcançados, em cada plano, no desempenho dos papéis virtuais do instrumento.

Relativizava-se com esse conceito o valor e o significado do plano. Ele não podia ser considerado a priori nem bom nem mau, pois seu sentido e seu caráter inovador seriam aqueles que viessem a Ihe ser atribuídos pelas forças sociais portadoras de vontade e poder capazes de influir decisivamente em sua produção. À medida que fosse democraticamente elaborado o plano teria, contudo, um mérito absoluto: ele constituiria uma oportunidade singular para todas as forças sociais conhecerem, debaterem e reelaborarem análises e proposições relativas a aspectos estruturais da dinâmica urbana, assumindo nesse processo níveis superiores de consciência, organização e responsabilidades.

Assim sendo, "fazer o plano" ganhava um significado especial: era uma oportunidade de produção, de cidadãos capazes de assumir o papel de legítimos autores do plano e, mais ainda, uma oportunidade de produção de um Estado capaz de sustentar novas práticas de planejamento e gestão transformadoras da cidade.

Plano diretor como missão de estado irrecusável para um governante responsável
O capítulo 5 relata a reflexão dos planejadores sobre o papel-chave do governante que promovesse a elaboração do plano diretor.

Alude-se aí a importância básica dele assumir uma Missão de Estado (inédita em muitos aspectos): viabilizar a produção socializada de um plano diretor. Este já se definira como um plano capaz de aproveitar os limitados recursos financeiros, materiais e institucionais disponíveis para orientar o desenvolvimento urbano no sentido de resultados inovadores, impossíveis de serem obtidos pelas práticas correntes. Agora ele teria também de ser reconhecido como expressão da vontade coletiva manifestada de forma inequívoca. Tornava-se claro que para tanto teria sido preciso 
conferir plena confiabilidade ao empreendimento, garantindo-Ihe qualidades essenciais como, por exemplo, legitimidade como processo democrático, embasamento técnico-científico e operacionalidade administrativa. Assegurar essas qualidades e assumir o compromisso político de que o plano seria concluído e implementado estariam entre os metaobjetivos identificados como essenciais à Missão de Estado subjacente a sua produção.

A tese procura demonstrar que para promover esse empreendimento com a isenção e competência indispensáveis à sua tarefa, o governante teria de conduzi-lo segundo uma estratégia especial, cuja caracterização é ali apresentada. Seria uma estratégia da estratégia, destinada a aproveitar o processo de elaboração do plano para se avançar ao máximo no sentido do desempenho de determinados papéis virtuais que o instrumento poderia jogar, dentre aqueles escolhidos como de maior interesse para o conjunto da sociedade e para o desempenho do Estado.

O último capítulo apresenta as conclusões parciais de cada capítulo e conflui para a síntese geral do trabalho. Indica-se como conclusão central da tese a idéia de que o plano diretor configura-se, nesse final de século, como uma oportunidade histórica incomparável da sociedade avançar no sentido da condução democraticamente deliberada do processo urbano para um novo patamar de eficiência econômica, eqüidade social e qualidade ambiental, patamar que surge como indispensável à inserção da metrópole em uma economia cada vez mais globalizada.

Mais precisamente: uma oportunidade da sociedade, utilizandose dos recursos institucionais e administrativos do Estado e das prerrogativas constitucionais do instrumento plano diretor, consagrar objetivos, princípios e diretrizes escolhidos como prevalentes e criar os instrumentos hábeis para alterar concretamente, nesse sentido, o processo urbano em curso.

Essa oportunidade será ou não aproveitada conforme os diferentes atores sociais e os detentores do poder do Estado assumam sua responsabilidade de contribuir para a obra coletiva, gerando progressos decisivos, tanto no campo da cooperação politicamente possível de ser estabelecida na sociedade para gerar as pretendidas transformações estruturais do processo urbano, como no campo da competição entre forças sociais
$O$ desafio persistente na virada do século: Um plano diretor eficaz produzido por uma prática democrática 
portadoras de interesses contraditórios, onde a negociação sistemática de novas regras do jogo teria de ser viabilizada.

Finalmente, alude-se ao papel especial que caberia a uma parcela da sociedade civil, inclusive a universidade, cuja importância cultural e política Ihe permite resgatar as potencialidades do instrumento plano diretor, bem como atuar no sentido de induzir os governantes e demais agentes sociais a compartilhar as responsabilidades da realização de uma experiência social e política ainda inédita: produzir um plano diretor criativo e eficaz em um contexto plenamente democrático.

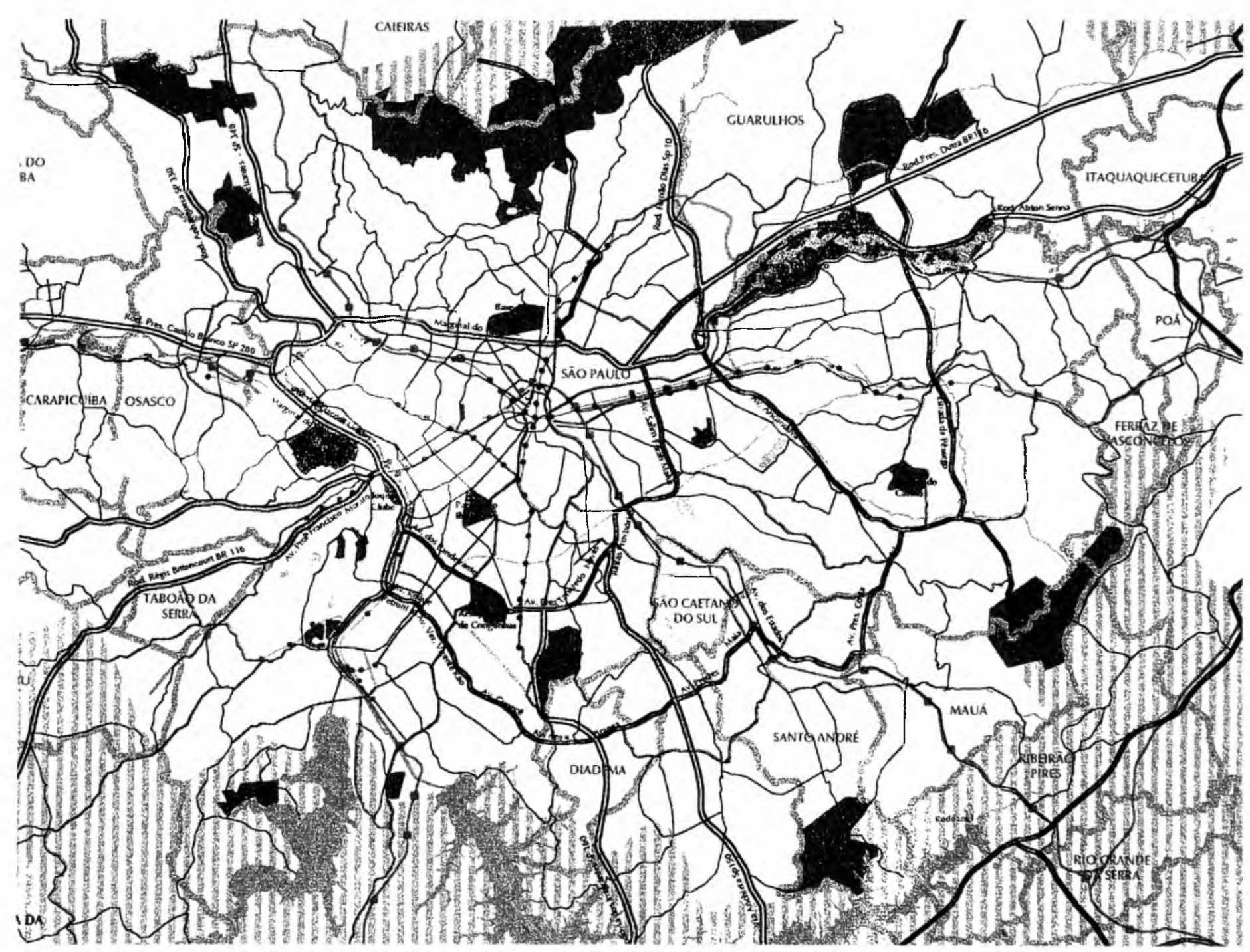

Fonte: Emplasa 